\title{
Solution to through the looking-glass challenge
}

\author{
Reinhard Meusinger ${ }^{1}$ \\ (C) Springer-Verlag GmbH Germany, part of Springer Nature 2018
}

The winner of the through the looking-glass challenge (published in volume 409, issue 25) is Wolfgang Robien, Institute of Organic Chemistry, University of Vienna, Vienna, Austria.

The award entitles the winner to select a Springer book of his choice up to a value of $€ 100$.

Our congratulations!

\section{Solution}

Compound $\quad(R)-(-)$-Carvone and $(S)-(+)$-carvone

name:

IUPAC name: 2-Methyl-5-(prop-1-en-2-yl)cyclohex-2en-1-one

Molecular $\quad \mathrm{C}_{10} \mathrm{H}_{14} \mathrm{O}$

formula:

Molar mass: $\quad 150.22 \mathrm{~g} / \mathrm{mol}$

This article is the solution to the Analytical Challenge to be found at https://doi.org//10.1007/s00216-017-0539-8

\section{Reinhard Meusinger}

meusi@nmr.chemie.tu-darmstadt.de

1 Institute of Organic Chemistry and Biochemistry, Darmstadt

University of Technology, Alarich-Weiss-Str. 4,

64287 Darmstadt, Germany
The substances sought are $(R)-(-)$-carvone and $(S)-(+)-$ carvone:<smiles>C=C(C)[C@H]1CC=C(C)C(=O)C1</smiles><smiles>C=C(C)[C@H]1CC=C(C)C(=O)C1</smiles> 